\title{
Financial Technology: China's Stock Markets vs U.S. Stock Markets
}

\author{
Ruiqian Chang ${ }^{1, *}$ \\ ${ }^{1}$ Cass Business School Accounting and Finance London, United Kingdom
}

\begin{abstract}
This paper provides a detailed analysis of the difference between the Chinese stock market and the U.S. stock market under the development of financial technology. In conclusion, we find that the Chinese stock market is more dominated by retail investors, but the United States owns more stocks, mostly held by institutional investors, and has a better financial mindset. The behavior of investors in the Chinese stock market is mainly the excessive speculation of investors in the Chinese market. This is one of the reasons for the many fluctuations in the Chinese stock market. Due to the speculative nature of China's stock market, the floating ratio reflects the management mechanism of China's stock market and helps to observe the correlation with the U.S. stock market. And technology and digitalization affect the trading of the stock market. This research is correlational, and there is no causality implied.
\end{abstract}

\section{Introduction}

According to the US Securities and Exchange Commission, as current technology has affected the development of the stock market, investors can obtain information about the company and its stocks. The Internet provides current stock prices and news of companies issuing shares. These latest developments can be communicated to customers, and companies can track the performance of their stocks. The result of this information is to enable investors, traders and advisors to fully understand the situation. This article is to study the differences between the Chinese and American stock markets under the Internet.

China's stock market operates differently from the U.S. market. It owns unique differences, such as the different types of economic systems, the background of culture, government policy, and investment behaviors. This paper will focus on both the Chinese and U.S. stock markets, together with the differences between them.

First, the Chinese stock market is younger than the U.S market. Though the history of Shanghai Stock Exchange (SSE) dates as early as the $1860 \mathrm{~s}$, SSE was shut down until 26 November 1990, ever since Communist Party came to power. In the same year, the Shenzhen Stock Exchange (SZSE) was established, marking China's stock market only 29 years old. However, the Chinese stock market has experienced dramatic growth. Currently, the Chinese stock market has become the second-largest market in Asia after Japan and the world's largest emerging market.

By contrast, the American stock market has a history of 223 years, and the New York Stock Exchange (NYSE) derived from the Buttonwood Agreement was signed on Wall Street in 1972. Since then, many other U.S. stock exchanges have burgeoned. The United States Securities and Exchange Commission (SEC) lists approximately 25 registered national stock exchanges, with the secondlargest exchange after NYSE, the NASDAQ (Nasdaq) established in 1971.

China's economy has developed rapidly in recent years. The Chinese stock market has become the center of world attention. Also, due to the development of technology, investors are provided with a way to research and buy stocks. The Chinese financial markets have gradually opened to foreign investors, attracting many foreign investment banks and financial organizations to invest in the Chinese market. Overseas investors are increasingly participating in investing in stocks in China. Consequently, the performance of the Chinese stock market has become increasingly important both to domestic and foreign investors.

The structure of this paper is as follows. Section 2 discusses the economics between the Chinese stock market and the U.S. stock market under the advancement of technology. Section 3 focuses on the culture's background about the difference between the two stock markets. Section 4 discusses the two-stock market relation to other markets such as gold and housing. Section 5 discusses the impact of the new coronavirus on the stock markets of the two countries in 2020. Section 6 combines the preceding sections to introduce firm financial reports and analyst forecasts. Moreover, the last section contains a summary and conclusion.

\section{$2 \mathrm{~A}$ tale of economies}

China's stock market has developed rapidly since its establishment and has become increasingly important for international investors. China's low labor costs and cheap

*Ruiqian.Chang@city.ac.uk

(C) The Authors, published by EDP Sciences. This is an open access article distributed under the terms of the Creative Commons Attribution License 4.0 
supplies of materials have attracted many global manufacturing companies, whose manufacturing divisions are located in China. It enables companies to produce goods cheaply, which also explains why many of the products we use in daily lives are made in China. However, this phenomenon has a negative impact on the U.S. export market. Despite being the world's largest exchange, China's stock market is still young; China plays an important role in the U.S. economy. A rational investor considers both risks and returns. We can see from Tab. 1 that the Sharpe ratio in the Chinese stock market is higher than that in the U.S. stock market. So stocks make up a large portion of American household wealth, with about $50 \%$ of the population owning stocks. In Contrast, Chinese investors hold more portfolios in real estate, wealth management products, and bank deposits.

Table1. Sampling data collection during two sampling periods

\begin{tabular}{|c|c|c|c|c|c|}
\hline & Mean & $\begin{array}{c}\text { Standard } \\
\text { Deviation }\end{array}$ & Sharpe Radio & Minimum & Maximum \\
\hline GSPC & 0.00619208 & 0.05358316 & 0.11556022 & -0.2994228 & 0.39137645 \\
\hline HSI & 0.00892477 & 0.073496 & 0.121432 & -0.440993 & 0.30280982 \\
\hline SZ & 0.01805335 & 0.12555032 & 0.14379377 & -0.2351594 & 0.83870283 \\
\hline SS & 0.01764183 & 0.15558625 & 0.11338937 & -0.3115295 & 1.77226177 \\
\hline
\end{tabular}

\section{Cultural Background}

With the development of the Internet, the differences between the Chinese and American stock markets so obvious. Although the US stock market is dominated by institutions that tend to value value and long-term investment, the Chinese stock market is dominated by retail investors who follow trends and catch up with rising trends. The market is not efficient enough. According to some studies, the level of retail investors in China's stock market is several times higher than that in the U.S. In investing, U.S. retail investors are more dependent on institutional investors, and they prefer to leave their money with institutional investors, so they do not work as hard as their China retail investors. According to the analysis of Yang, Y. F. (2020), the U.S. stock market is a mature market relative to the Chinese stock market, because volatility is less than that of the Chinese stock market, and it can provide people with a stable environment to manage their funds. As the Chinese stock market is immature, the Chinese stock market is still dominated by retail investors. The simplicity of most Chinese investors is that they view the Chinese stock market as a crazy vegetable market, not as a tool for economic growth. Chinese shareholders only like to buy stocks. They always invest more money when the stock market rises and then complain when the stock market crashes. Most of them still believe that relying on themselves is just vital, so they have not established a good investment mentality. However, it is because the U.S. stock market, which includes much stricter regulation of listed companies, is much more regulated than the Chinese stock market. Not only is the operation of U.S. listed companies very standardized, including information disclosure is highly transparent, but it also facilitates investors to make correct investment decisions. Therefore, investors only need to master the fundamentals of listed companies to make correct investment decisions.

Chinese investors are irrational when buying stocks. They always fantasize about getting rich through stocks, but this can lead to serious problems such as frequent and cheap transactions, blind tilt and blind use of leverage. Generally, the higher yield of the stock market is always defined on a long-term basis. If one only use high leverage to bet on the rise and fall of a stock over a week, the risk must be very high. However, those investors who want to make more money a day or even more do not want to give up the opportunity to make money, they will enter and exit all transactions between various hot spots in the market almost every day. When they make a profit, they will invest more money. On the contrary, they will not withdraw when they lose money but will do everything they can to make up for the loss. A typical phenomenon is that when one makes a profit, one feels good about oneself, and one finds the reason after losing money.

At present, the stock markets of most countries in the world, including the United States, have no daily limit. The Chinese stock market did not have a daily limit initially until the realization that the intense speculative atmosphere had led to the sharp rise of the stock market and the peak of volatility. Most people would think that this rule is to protect the interests of small and medium investors and prevent stock price fluctuations from affecting small and medium investors. A maliciously created market will affect the financial market with greater volatility, but as a result, all participants will be affected by this volatility. Blind obedience and overreaction in human nature are taken advantage of by this mechanism and apply to all participants. Therefore, starting from 16 December 1996, the Shenzhen Stock Exchange has implemented a limit of $10 \%$ for the listed stock exchange.

In the development of the U.S. stock market, it can be confidently stated that most of the periods were soaring. In contrast, crashes of the Chinese market are quite frequent, and it is highly similar to the early phase of the U.S. market. It has not become a reason why the U.S. government can exert logic control over the stock market. The stock market panic of 1907 drawn the U.S. government's attention to the manipulation and speculation of the stock market. The Hughes Commission began in 1908 to investigate the manipulation of the U.S. securities market, including the futures market. The Hughes Commission's investigation report pointed to manipulation and speculation on the New York Stock Exchange. But it is recommended that the US government not take drastic actions to change Wall Street trading rules, but only call on exchange participants to strengthen selfdiscipline.

Although the United States has no limit on the rise or fall, the U.S. stock market, which has a history of more than 100 years, is still more mature than the Chinese stock market. The volatility of the U.S. market is also small. We can see from Fig. 1 that the Chinese market is more volatile than the U.S. market, and the average stock price in the Chinese market is much larger than the average stock price in the U.S. market. So, why does China have a 
daily limit while the U.S. does not? The reason is that the stability mechanisms of the two countries' stock markets are different, which is determined by the history of the stock markets and even the social systems.

\section{Relation to other markets (Gold, Housing, etc.)}

Under most circumstances, gold has been considered a haven for volatile markets. Regardless of international economic and political turbulence or market inflation, investors

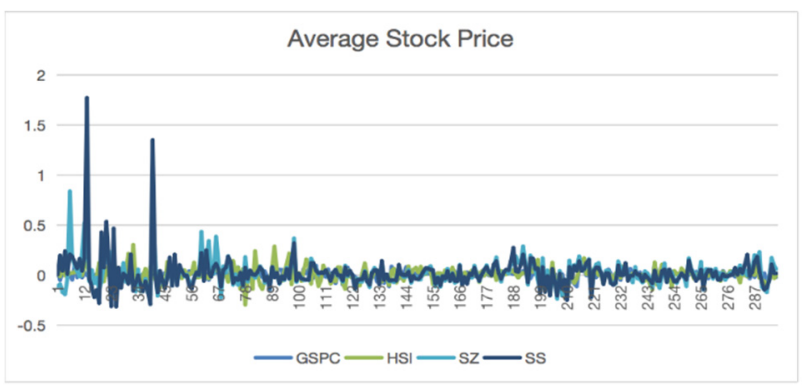

Figure 1. Summary statistics for Average Stock Prices differences in different regions of the two countries

can choose gold to fight against. When the stock market falls, or the economy grows too fast, the price of gold will rise. The stock market and the gold market are often the most important two of the asset portfolio selection markets. Funds in the capital market pursue long-term returns. Under typical circumstances, when the stock is in an upward trend, investors are more willing to invest in stocks to profit directly or funds of the gold market to chase the high returns of stock investment, resulting in a decline in gold prices. Moreover, the market economy is not operating adequately, and the spontaneous adjustment of the market cannot achieve full employment. When the stock market is in a mid-to-long-term bear market, some funds will flow back to the gold market, causing the gold price to rise. However, the impact of stocks on gold is not static, and sometimes it can be broken due to various factors.

The U.S. dollar closely influences the fluctuation of gold prices. The relationship between the U.S. dollar and gold is a reverse interaction. International gold is denominated in the international currency, U.S. dollar. When the U.S. dollar rises, the price of gold will relatively fall. In most cases, the rise of U.S. stocks will lead to the rise of commodities led by Crude Oil and gold. However, under the global debt crisis, poor liquidity and debt crises will prompt countries and consortia to hold large amounts of gold and sell gold in cash currencies such as U.S. dollars, thus saving the weak market economy and boosting financial markets. The performance during this period was: the price of gold fell rapidly, and the stock market rebounded.

However, even with the poor performance of the stock market, the gold market did not improve much during this period. In fact, the gold market did not take off until the mid-1970s. As shown in Fig. 2, the price of gold fluctuated greatly, especially in 1970 . However, at the same time, the
U.S. federal basic interest rate was as high as $20 \%$, then soaring crude oil prices pushed up the inflation rate. In other words, during this period, the price of gold and inflation soared at the same time.

As for 2000, the world has ushered in a decade of higher inflation. However, unlike the high inflation in the 1970 s, Table 3 shows that the high inflation rate in the 1970s was driven by supply. As for the beginning of the millennium, it was demand-driven, and the huge potential domestic demand in emerging countries drove the GDP to soar.

The stock market is closely interrelated with the economy. Changes in the real estate market may affect the stock market

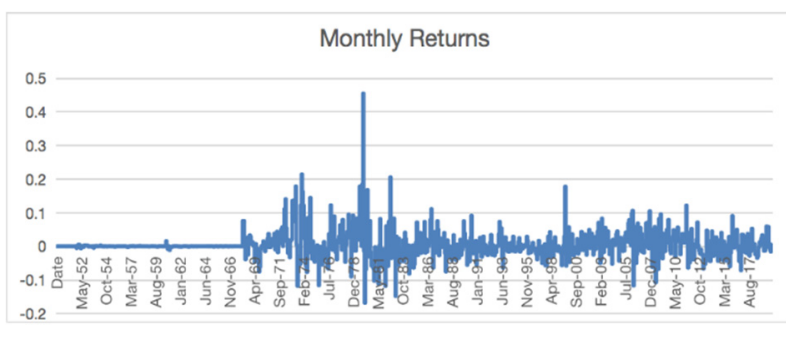

Figure 2. Average Monthly Returns of gold price: January 1950 to December 2019

to a certain extent, but unlike China, according to Huang, Zhang and $\mathrm{Li}(2020)$,research shows that there is a longterm equilibrium between the Chinese stock market and the real estate market, but the trend of real estate stocks in the U.S. stock market is highly correlated with housing prices. It can be seen in Tab. 2 that the U.S. house price index is higher than the China house price index. Also, we compared the variance of the house market index of the two markets, finding that the volatility of the index is higher than the U.S. house price index.

Table2. Summary sampling data statistics for Housing Price Index between China and U.S.

\begin{tabular}{|c|c|c|c|c|}
\hline & Variance & Mean & $\begin{array}{c}\text { Standard } \\
\text { Deviation }\end{array}$ & Median \\
\hline China & 409.140682 & 103.851404 & 16.03474883 & 104.2 \\
\hline U.S. & 257.11317 & 168.332439 & 20.22722625 & 167.327 \\
\hline
\end{tabular}

\section{Covid-19 on the stock markets}

Since COVID-19 first appeared in Wuhan, China, by the end of 2019, the Chinese stock market experienced a decline, causing serious economic losses to China, but the stock markets in Shanghai and Shenzhen have been relatively resilient. At first, the outbreak stage of COVID19 only attracted national attention; even if the virus began to spread around the world at first, all countries treated it as a cold and did not care much. Since COVID-19 first appeared in Wuhan, China, by the end of 2019, the Chinese stock market experienced a decline, causing serious economic losses to China, but the stock markets in Shanghai and Shenzhen have been relatively resilient. At first, the outbreak stage of COVID-19 only attracted 
national attention; even if the virus began to spread around the world at first, all countries treated it as a cold and did not care much. Investors are worried about the volatility of the stock market, and China's economy has fallen dramatically. When the epidemic in China is gradually brought under control, the COVID-19 outbreak abroad has already begun. As shown in Fig. 3 and Fig. 4, the epidemic in China has slowly stabilized, and since the beginning of February, the United States and other countries outside China have increased exponentially.

\section{Summary}

Will the Chinese stock market surpass the U.S. stock market one day? The stock markets of China and the United

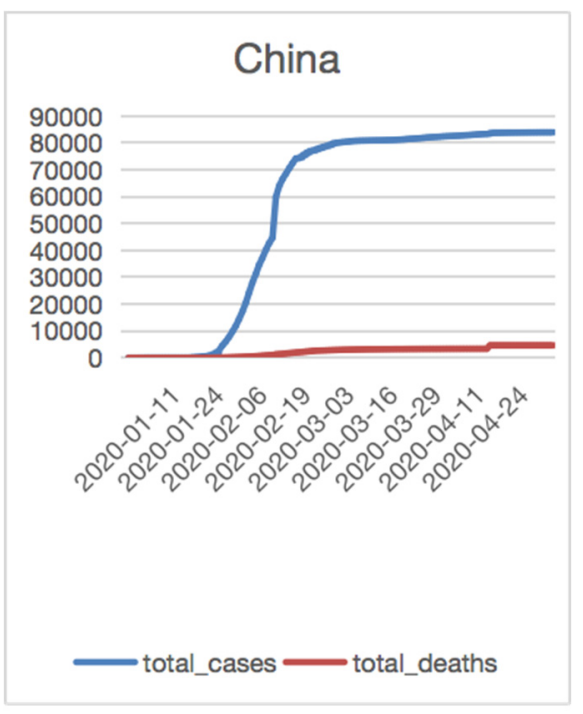

Figure 3. Coronavirus from Feb 2020 to May 2020 for China

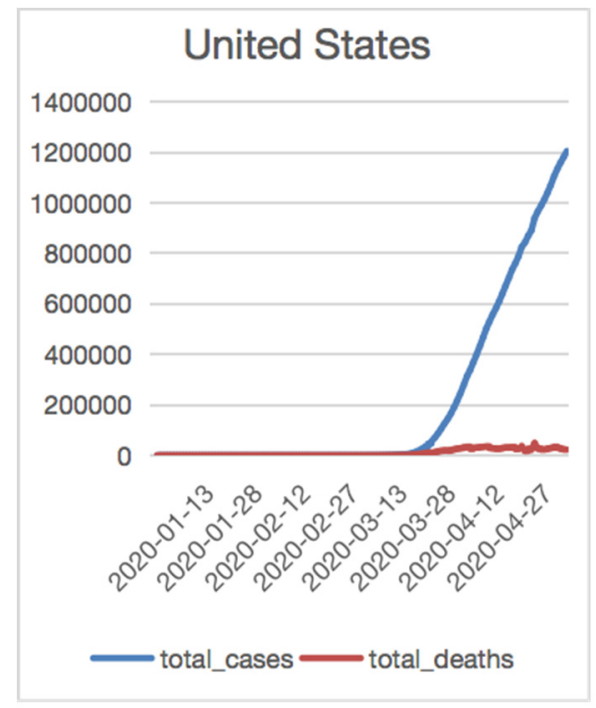

Figure 4. Coronavirus from Feb 2020 to May 2020 for U.S. stock market

States are distinct in many ways. First, the Chinese stock market is still young in its 30 s, while the U.S. stock market is around 200 years old. Second, China and the United States have different soft stock markets, different social systems, legal environments, humanities, ideologies, and so on. These have greatly affected the stock markets of the two countries.

The first is the daily limit set by China, which controls the upper and lower limits of daily trading fluctuations, which makes a large impact, which takes several days to release, and the degree of freedom of trading is limited to a certain extent. The U.S. market, except for some special circumstances, generally does not stop trading and does not interfere with the stock spread. Second, in China, because there are many state-owned enterprises in the hands of the government, the

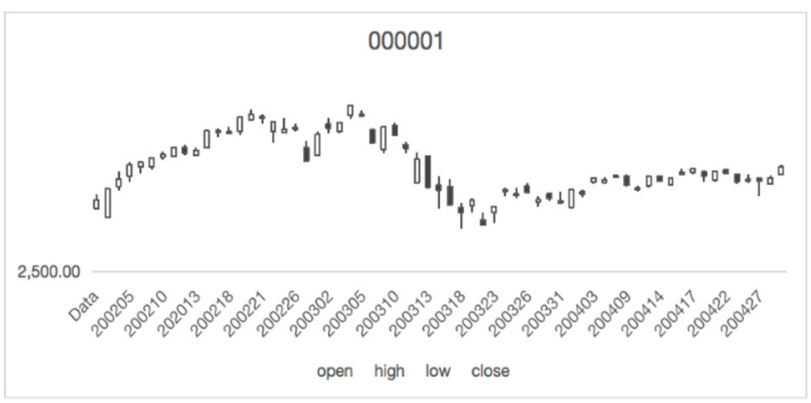

Figure 5. The charts of 000001 stock index, with White bars represent stocks rising and Black bars represent stocks falling.

government is the largest shareholder, so there are many non- tradable shares, which tends to cause relatively few tradable shares and large fluctuations in the stock. In contrast, the U.S. government generally only uses Enterprise shares are through pensions, social security funds, etc., and are managed by specially designated professional companies. The proportion of investment in individual stocks is generally small, which will not affect circulation. Of course, solving the issue of liquidity can increase the number of shares issued, but if the amount is too large, it will cause the long-term growth of the stock value to slow down and affect the enthusiasm of shareholders.

China's stock market is largely manipulated by market makers, whose primary purpose is to reap short-term profits. In addition, Chinese listed companies have little dividends, which means that the stock market is more speculative. Many institutions in the U.S. stock market, including pensions and pensions, invest Institutions generally aim for long-term or dividend returns, and their operations are not obvious.

When the global coronavirus epidemic broke out, the global stock market fluctuated considerably. But the main reason that the Chinese stock market is relatively stable lies in that China had prepared in advance in the structural reform of the financial supply side when the epidemic occurred, which alleviated the hidden risks in the capital market. Therefore, as shown in Fig. 5, the risk in the Chinese market has stayed low, and the liquidity in the Chinese market has been relatively abundant. In contrast, in the U.S. market, the stocks are much more volatile and susceptible to the pandemic. On 16 March, Beijing time, U.S. stocks fell across the board. The opening of the three major US stock indexes triggered the first layer of $7 \%$ fuse, which is also the third time in the past two weeks and the fourth U.S. stock market meltdown. The sell-off in the 
international financial market happened to not only U.S. stocks, but the stock markets of many countries. Fig. 6 shows that Standard \& Poor 500 Index (S\&P 500) is very volatile during March, for example, as of the close of U.S. stocks on 16 March, the candle body on this day is very long, indicating a massive decline. The three major US stock indexes closed down by more than $11 \%$, the worst day since the 1987 "Black Monday" market crash, and the history of three meltdowns in January. The S\&P 500 index fell $11.98 \%$ to close at 2386.13 points.

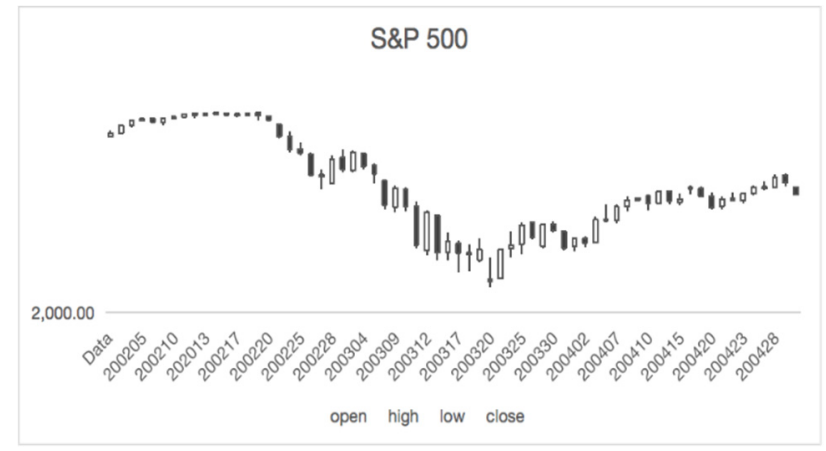

Figure 6. Standard \& Poor 500 Index (S\&P 500), with White bars represent stocks rising and Black bars represent stocks falling.

In summary, on the basis of the existing literature, the research results of this paper further clarify the linkage relationship between the Chinese stock market and the U.S stock market and more effectively sort out the differences between the Chinese stock market and the U.S. stock market for investors. Based on computer statistics, we collected data on the difference between the US stock market and the Chinese stock market, and found that the U.S. stock market is more mature than the Chinese stock market, but by improving the economy, the Chinese stock market will soon be as mature as the U.S. stock market. The results of this article also provide some newer insights.

\section{References}

1. Y. Yufan, "Comparison and Analysis of Chinese and United States Stock Market," Journal of Financial Risk Management. vol. 9(01), pp. 44, March 2020.

2. L. Huadong, "Analysis of the Differences and Linkage between Chinese and American Stock Markets," J. ajIbm., vol. 8, pp. 700-709, March 2018.

3. M. Gavin, "The Stock Market and Exchange Rate Dynamics,” J. Imf., vol. 8, pp. 181-200, June 1989.

4. Z. Bing, F. Zhizhen and L. Xindan, "Study on the linkage of the stock market in China and America," J. Er, vol. 11, pp. 141-15, January 2010.

5. N. Janet, "Market reactions to COVID-19: Stocks end the week in decline," May 2020.

From:

https://www.marketplace.org/2020/05/01/how-themarkets-are reacting-to-covid-19/.

6. Ádám Kerényi and János Müller, "Brave New Digital World? - Financial Technology and the Power of
Information," Financial and Economic Review, vol. 18(1), pp. 5-32, March 2019.

7. Abad-Segura, E.; González-Zamar, M.-D.; LópezMeneses, E.; Vázquez-Cano, E. "Financial Technology: Review of Trends, Approaches and Management," Mathematics, vol.8, pp. 951, June 2020.

8. D. Zhang, M. Hu and Q. Ji, "Financial markets under the global pandemic of COVID-19," J. Frl., vol. 36, pp. 101528, April 2020.

9. N. Barberis and A. Shleifer, "Style Investing," J. Fe., vol. 68, pp. 161-199, May 2003.

10. Uscc.gov. 2020. 2020 Annual Report To Congress. From: https://www.uscc.gov/annual-report/2020annual-report-congress. 